\title{
Incidence and determinants of diabetes- related lower limb amputations in Ghana, 2010-2015- a retrospective cohort study
}

\author{
Osei Sarfo-Kantanka ${ }^{1 *}$ DD, Fred Stephen Sarfo ${ }^{1,2}$, Ishmael Kyei ${ }^{1}$, Charles Agyemang ${ }^{3}$ and Jean Claude Mbanya ${ }^{4}$
}

\begin{abstract}
Background: Diabetes-related lower limb amputations (LLA) are associated with significant morbidity and mortality. Although the incidence has decreased over the past two decades in most High-Income Countries, the situation in Low-Middle Income Countries (LMIC), especially those in sub-Saharan Africa (SSA) is not clear. We have determined the incidence and determinants of diabetes-related LLA in Ghana.

Methods: This was a tertiary-care-based retrospective cohort study involving patients enrolled in the diabetes clinic of Komfo Anokye Teaching Hospital, Ghana from 1st January 2010 to 31st December 2015 after a median follow-up of 4.2 years. Demographic characteristics and clinical variables at baseline were recorded. The primary outcome was new diabetes-related LLA in each year under study. Cox proportional hazard regression models were used to describe the associations of diabetes-related LLA.

Results: The mean age at enrolment for the cohort was $55.9 \pm 14.6$ years, with a female preponderance (62.1\%). The average incidence rate of diabetes-related LLA was 2.4 (95\% Cl:1.84-5.61) per 1000 follow-up years: increasing from 0.6\% (95\% Cl:0.21-2.21) per 1000 follow up years in 2010 to 10.9\% (95\% Cl:6.22-12.44) per 1000 follow-up years in 2015. Diabetes-related LLA was associated with increased age at enrollment (for every 10 year increase in age: HR: 1.11, Cl: 1.06-1.22, $p<0.001$ ), male gender (HR: 3.50, Cl:2.88-5.23, $p<0.01$ ), type 2 diabetes (HR 3.21, Cl: 2.58-10.6, $p<0.001$ ), high Body Mass Index (HR: 3.2, Cl: 2.51-7.25 $p<0.001$ ), poor glycemic control (for a percent increase in HbA1C, HR:1.11, Cl:1.05-1.25, $p=0.03$ ), hypertension (HR:1.14, Cl:1.12-3.21 $p<0.001$ ), peripheral sensory neuropathy (HR:6.56 Cl:6.21-8.52 $p<0.001)$ and peripheral vascular disease (HR: 7.73 Cl: 4.39-9.53, $p<0.001)$.

Conclusion: The study confirms a high incidence of diabetes related-LLA in Ghana. Interventions aimed at addressing systemic and patient-level barriers to good vascular risk factor control and proper foot care for diabetics should be introduced in LMICs to stem the tide of the increasing incidence of LLA.
\end{abstract}

Keywords: Diabetes, Lower limb amputation, Ghana

\section{Background}

Diabetes complications continue to increase parallel to the exponential increase in the incidence of the disease worldwide [1, 2]. The greatest burden of these complications can be found in Low-Middle Income Countries (LMIC) of the world [3, 4]. Disorders of the foot represent one of the most prevalent and feared of the complications of diabetes [5]. It portends a high risk of lower

\footnotetext{
* Correspondence: osarfokantanka21@gmail.com

${ }^{1}$ Komfo Anokye Teaching Hospital, Endocrine and Diabetes Unit, P.O Box

1934, Kumasi, Ghana

Full list of author information is available at the end of the article
}

limb amputation (LLA) and mortality [6, 7]. Evidence from resource-rich industrialised world shows a decrease in the incidence of diabetes-related LLA by $48-78 \%$ after the introduction of multidisciplinary foot care clinics [8-10], specified referral pathways and stringent diabetes foot education [11-13].

Diabetes care in LMICs especially those in sub-Saharan Africa (SSA) is beset with inherent organisational deficits including fragmentation of care, inadequate allocation of resources and unwavering attention to achieving glycemic targets $[14,15]$. These factors have contributed to an increasing burden of complications prominent among them

(C) The Author(s). 2019 Open Access This article is distributed under the terms of the Creative Commons Attribution 4.0 International License (http://creativecommons.org/licenses/by/4.0/), which permits unrestricted use, distribution, and 
foot disorders [16, 17]. Although a high burden of non-traumatic LLA has recently been reported in Ghana [18], the role of diabetes on this burden is yet to be clarified.

The trajectories and determinants of diabetes-related LLA in LMICs are needed to provide a basis for comparison with incidence from other areas of high-quality diabetes care. Additionally, baseline data is required for the design and testing of locally appropriate foot care interventions if LLA from diabetes is to be reduced in LMICs.

This study aimed to determine the incidence of diabetes-related LLA in a cohort of patients enrolled in an outpatient tertiary clinic from 2010 to 2015. Secondly, we have identified the clinical factors that predict diabetes-related LLA in the cohort.

\section{Methods}

\section{Profile of study area and population}

We undertook a retrospective cohort study of patients who enrolled in the diabetes clinic of Komfo Anokye Teaching Hospital, a tertiary hospital in Kumasi, Ghana from 1st January 2010 to 31st December 2015. The hospital is situated in the central belt of Ghana and serves an estimated 10 million people from six out of the 10 regions of Ghana as well as other neighbouring countries. The diabetes clinic was established in 1992 and runs daily during the working week. Over 20,000 patients have enrolled in the clinic for follow up with the current active population estimated at 12,000 patients. The weekly attendance to the clinic range between 300 and 450 patients. The clinic is run by a team of Physicians/ Diabetologist, nurses and dieticians. The study was approved by the Committee on Human Research Publication and Ethics of the School of Medical Sciences, Kwame Nkrumah University of Science and Technology, and the Komfo Anokye Teaching Hospital, Kumasi. We anonymised patient's records/information before analysis.

\section{Data collection}

We trained research assistants for 2 days on how to retrieve and extract relevant data from medical records of patients and return the files back to their original location. The lead author examined approximately $10 \%$ of all data recording sheets for competence and consistency. We retrieved folders of patients who enrolled in the clinic from 1st January 2010 to 31st December 2015 by satisfying the criteria of the World Health Organisation for the diagnosis of diabetes i.e. an elevated fasting plasma glucose level ( $\geq 7 \mathrm{mmol} / \mathrm{L}$ ) on two occasions, or oral glucose tolerance test $\geq 11.1 \mathrm{mmol} / \mathrm{l}[19]$.

Data extracted from patient folders included demographic and relevant clinical information at enrolment; age, gender, age at diagnosis, alcohol intake and smoking status. Others included weight $(\mathrm{kg})$, body mass index (BMI), blood pressure, glycated haemoglobin (HbA1c), lipid profile and estimated Glomerular Filtration Rate (eGFR). Neuropathic and vascular symptoms including paresthesia, intermittent claudication were recorded. Peripheral neuropathy $(\mathrm{PN})$ was diagnosed using a combination of symptoms such as paresthesia's, numbness as well as monofilament and vibration sense testing. Peripheral artery disease (PAD) was diagnosed based on symptoms such as intermittent claudication allied to ankle-brachial index measurements (less than 0.9), Doppler ultrasonography and magnetic resonance imaging angiography. Patients who had undergone diabetes-related LLA including when, type and the limbs affected were identified from the folders and recorded. This information was crosschecked from the theatre records of the hospital in most cases KATH where the surgeries were done. Any LLA performed distal to the ankle joint was classified as minor, whiles any LLA performed through or proximal to the ankle joint was classified as major. [20] We excluded patients who had a diabetic foot ulcer at enrolment, as well as those with diabetes-related LLA before enrolment to focus on only patients who developed foot ulcers and LLA after enrolment into the diabetes clinic. We also excluded patients who were lost to follow up or those who died before completing one full year of follow up after enrolling in the clinic.

\section{Statistical analysis}

We described data using means and medians and compared them using either the Student t-test or Mann Whitney U-test for paired comparisons depending on whether the variables were parametric or non-parametric. We tested differences in frequencies for significance using the Chi-square test or Fishers Exact tests. We calculated incidence rates as the number of patients with new LLA per the total study group person-years. We created Cox proportional hazard regression analysis models to determine factors that predicted LLA in the cohort. Variables included in the model were: age (years) at presentation, gender, type of diabetes, lipid status, renal function, and symptoms of peripheral neuropathy. Statistical significance was set at a $p$-value of $<0.05$ (two-sided). Statistical analysis was performed using Graph Pad Prism 7 and SPSS ver. 20.

\section{Results}

\section{Characteristics}

A total of 3722 patients enrolled in the diabetes clinic between 1st January 2010 and 31st December 2015. We excluded 127 of them because they presented to the clinic with foot disorders and 325 because they had been lost to follow-up before a year of enrolment had passed. A total of 3143 patients were therefore included in the 
Table 1 Baseline characteristics of patients by presence of Lower Limb Amputation in diabetes clinic, 2010-2015

\begin{tabular}{|c|c|c|c|c|}
\hline Parameters & $\begin{array}{l}\text { Combined } \\
(n=3143)\end{array}$ & $\begin{array}{l}\text { Lower Limb Amputation } \\
(n=78)\end{array}$ & $\begin{array}{l}\text { No Lower Limb Amputation } \\
(n=3065)\end{array}$ & $p$-value \\
\hline \multicolumn{5}{|l|}{ Gender } \\
\hline Female, n (\%) & $1952(62.1)$ & $30(38.5)$ & $1922(62.7)$ & $<0.001$ \\
\hline Age, mean $\pm S D$ & $59.5 \pm 14.6$ & $62.2 \pm 11.8$ & $58.5 \pm 14.9$ & 0.02 \\
\hline Age at diagnosis, mean \pm SD & $49.2 \pm 11.2$ & $46.2 \pm 10.2$ & $52.2 \pm 11.6$ & $<0.001$ \\
\hline Duration of diabetes & $10.2 \pm 5.6$ & $10.9 \pm 6.8$ & $9.6 \pm 4.9$ & 0.08 \\
\hline Location of domicile & & & & 0.29 \\
\hline Urban & $2567(81.7)$ & $52(56.7)$ & $2515(82.1)$ & 0.002 \\
\hline Semi-urban & 409 (13.0) & $8(10.3)$ & $401(13.1)$ & 0.61 \\
\hline Rural & $167(5.3)$ & $18(23.1)$ & $149(4.7)$ & $<0.001$ \\
\hline Highest educational attainment & & & & 0.03 \\
\hline None & $454(14.3)$ & $23(29.5)$ & $431(14.1)$ & $<0.001$ \\
\hline Primary & $604(19.2)$ & $23(29.5)$ & $601(19.6)$ & 0.04 \\
\hline Secondary & $1389(44.2)$ & $26(33.3)$ & $1644(53.6)$ & $<0.001$ \\
\hline Tertiary & $695(22.1)$ & $6(7.8)$ & $389(12.7)$ & 0.23 \\
\hline \multicolumn{5}{|l|}{ Employment status } \\
\hline Skilled academic & $298(9.5)$ & $21(26.9)$ & $277(9.0)$ & $<0.001$ \\
\hline Manual worker & $1763(56.1)$ & $32(41.0)$ & $1731(56.4)$ & 0.01 \\
\hline Retired & $426(13.6)$ & $16(20.5)$ & $410(13.4)$ & 0.09 \\
\hline Unemployed & $517(16.4)$ & $9(11.5)$ & $508(16.8)$ & 0.28 \\
\hline Duration before referral to Centre, mean \pm SD (years) & $3.8 \pm 2.5$ & $5.4 \pm 1.7$ & $1.3 \pm 2.2$ & 0.001 \\
\hline Diabetes type & & & & 0.25 \\
\hline Type 1 & $192(6.1)$ & $2(2.6)$ & $156(5.1)$ & 0.43 \\
\hline Type 2 & $2793(88.9)$ & $76(97.8)$ & $2717(88.6)$ & 0.001 \\
\hline Others & $168(5.3)$ & $0(0)$ & $192(6.3)$ & - \\
\hline \multicolumn{5}{|l|}{ Vascular risk factors } \\
\hline Hypertension, n (\%) & $2678(85.2)$ & $74(94.9)$ & $2604(84.6)$ & 0.02 \\
\hline Dyslipidemia, n (\%) & $1897(60.4)$ & $59(75.6)$ & $1838(60.0)$ & 0.004 \\
\hline Cigarette smoking n (\%) & $36(1.1)$ & $9(11.5)$ & $27(0.9)$ & 0.84 \\
\hline Alcohol Use, n (\%) & $756(24.1)$ & $18(23.1)$ & $738(24.1)$ & 0.43 \\
\hline Waist-to-Hip ratio, mean \pm SD & $0.93 \pm 0.09$ & $0.95 \pm 0.05$ & $0.94 \pm 0.08$ & 0.18 \\
\hline Body Mass Index, mean \pm SD & $28.0 \pm 3.3$ & $26.0 \pm 3.7$ & $27.1 \pm 3.6$ & 0.007 \\
\hline Systolic blood pressure, $\mathrm{mmHg}$ & $143 \pm 35.1$ & $156 \pm 43.1$ & $130 \pm 18.9$ & 0.0001 \\
\hline Diastolic blood pressure, $\mathrm{mmHg}$ & $89.3 \pm 23.2$ & $96.2 \pm 22.1$ & $82.4 \pm 14.4$ & 0.0001 \\
\hline \multicolumn{5}{|l|}{ Therapy } \\
\hline Lipid-lowering therapy, n (\%) & $1245(39.6)$ & $12(15.4)$ & $1233(40.2)$ & $<0.0001$ \\
\hline Antiplatelet therapy, n (\%) & $1345(42.8)$ & $23(29.5)$ & $1322(43.1)$ & 0.01 \\
\hline ACE/ARB Inhibition, n (\%) & $2567(81.7)$ & $35(44.9)$ & $2532(80.6)$ & $<0.0001$ \\
\hline Calcium channel blockers, n (\%) & $2064(65.7)$ & $64(82.1)$ & $2000(65.3)$ & $<0.0001$ \\
\hline Centrally acting agents, n (\%) & $478(15.2)$ & $13(16.7)$ & $465(15.1)$ & 0.75 \\
\hline Diuretics, n (\%) & $1567(49.9)$ & $12(15.4)$ & $1355(44.2)$ & $<0.001$ \\
\hline Metformin, n (\%) & $2975(94.7)$ & $48(61.5)$ & $2927(94.5)$ & $<0.001$ \\
\hline Sulphonylureas, n (\%) & $2456(78.1)$ & $63(80.8)$ & $2393(78.1)$ & 0.68 \\
\hline DPP4 Inhibitors, n (\%) & $102(3.2)$ & $1(1.3)$ & $101(3.3)$ & 0.52 \\
\hline
\end{tabular}


Table 1 Baseline characteristics of patients by presence of Lower Limb Amputation in diabetes clinic, 2010-2015 (Continued)

\begin{tabular}{|c|c|c|c|c|}
\hline Parameters & $\begin{array}{l}\text { Combined } \\
(n=3143)\end{array}$ & $\begin{array}{l}\text { Lower Limb Amputation } \\
(n=78)\end{array}$ & $\begin{array}{l}\text { No Lower Limb Amputation } \\
(n=3065)\end{array}$ & $p$-value \\
\hline Insulin, n (\%) & $624(19.9)$ & $2(2.6)$ & $622(20.3)$ & $<0.001$ \\
\hline \multicolumn{5}{|l|}{ Glycemic control } \\
\hline Fasting blood glucose (mmol/L) & $8.9 \pm 5.2$ & $12.6 \pm 5.6$ & $7.9 \pm 4.5$ & $<0.0001$ \\
\hline $\mathrm{HbA1c}(\%)$ & $8.1 \pm 2.1$ & $10.4 \pm 3.2$ & $7.5 \pm 4.2$ & $<0.0001$ \\
\hline Estimated Glomerular Filtration Rate & $42.2 \pm 9.8$ & $29.2 \pm 6.8$ & $66.4 \pm 5.6$ & $<0.0001$ \\
\hline Peripheral sensory neuropathy & $867(27.6)$ & $66(84.6)$ & $801(26.1)$ & $<0.0001$ \\
\hline Peripheral Vascular Disease & $87(2.8)$ & $26(33.3)$ & $61(2.0)$ & $<0.0001$ \\
\hline
\end{tabular}

n number, SD standard deviation, ACE angiotensin converting enzyme, ARB angiotensin receptor blocker, DPP4, dipeptidyl peptidase inhibitor, HbA1c glycated hemoglobin

analysis. The clinical characteristics of the patients included in the study are shown in Table 1 . The median duration of follow up was 4.2 years. The mean age at diagnosis was significantly lower among those with diabetes-related LLA. The mean duration of diabetes before referral to the diabetes clinic was significantly higher for those who underwent LLA. Almost all diabetes-related LLA occurred in type 2 diabetes patients (97.8\%). At baseline, those with LLA had significantly higher mean systolic and diastolic blood pressures, a higher proportion of dyslipidaemia, poorer glycemic controls and obesity (all $p<$ 0.001). Patients with LLA had lower rates of statins, antiplatelet therapy, ACE inhibitors and Angiotensin Receptor Blockers, metformin and insulin prescriptions at baseline compared to those without diabetes-related LLA $(p<$ 0.001). Symptoms of PSN and PVD were reported frequently in those with LLA at baseline compared to those without LLA (all $p<0.001$ ). There was no significant difference between those with LLA and those without LLA regarding alcohol use and cigarette smoking at baseline.

\section{Incidence of amputations}

The absolute number of diabetes-related LLA among our cohort increased from 2 in 2010 to 29 in 2015. The average incidence rate of diabetes related-LLA was 2.4 (95\% CI:1.84-5.61) per 1000 follow up years: increasing from 0.6 (95\% CI:0.21-2.21] per 1000 follow up years in 2010 to 10.9 (95\% CI:6.22-12.44) per 1000 follow up years in 2015 (Fig. 1).

\section{Causes of amputations}

The main causes of amputation included PVD, i.e. 63\% of LLA, PSN; 24 and $13 \%$ were due to a combination of the two (Fig. 2).

\section{Types of amputations}

$67.9 \%$ of LLA was classified as major LLA, $32.1 \%$ were minor. $42.3 \%$ of the LLA were above the knee, $28.2 \%$ were below the knee, $5.1 \%$ had bilateral above-knee amputations, and 5.1\% had bilateral below knee amputations. Of the 25 minor amputations: $15.3 \%$ had a right digital amputation, $10.3 \%$ had left digital amputation, and 6.4\% had bilateral digital amputations (Table 2).

\section{Predictors of lower limb amputations}

Independent factors associated with LLA in our diabetes cohort are shown in Table 3: age at presentation; every 10 -year increase in age increased the risk of LLA by $11 \%$, male gender was associated with 3.5 times increased the risk of LLA. Patients with type 2 diabetes had eight times increased the risk of LLA compared to those with other forms of diabetes. Every $5 \mathrm{~kg} / \mathrm{m}^{2}$ increase in BMI increased the risk of LLA three times. A percentage increase in $\mathrm{HbAlc}$ increased the risk of LLA by $11 \%$. The presence of hypertension increased the risk of LLA by $14 \%$. The presence of PSN and PVD increased the risk of LLA by about 7 and 8 -fold respectively.

\section{Discussion}

In this retrospective cohort study spanning a period of 6 years, the incidence of diabetes-related LLA within a diabetes cohort attending a tertiary referral centre in Ghana rose from 0.6 per 1000 follow up years in 2010 to 10.9 per 1000 follow up years in 2015. We identified

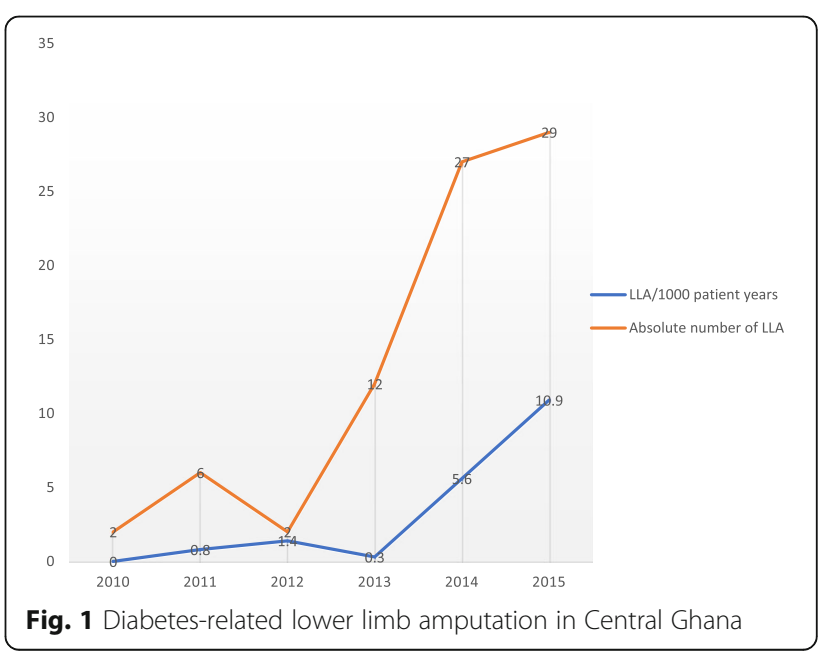




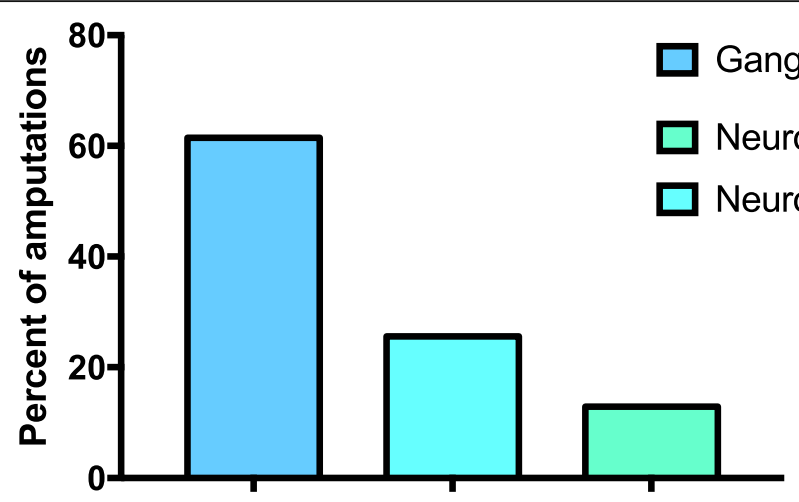

Fig. 2 Causes of diabetes-related lower limb amputations in central Ghana

gangrene/PVD as the leading cause of diabetes-related LLA in the cohort. Additionally, diabetes-related LLA in our cohort was associated with uncontrolled vascular risk factors and poor glycemic control at baseline. Our study thus confirms a high burden of foot disorders and diabetes-related LLA among diabetes patients in LMICs [16-18]. This finding is in contrast with those from industrialised countries where the incidence of diabetesrelated LLA has reduced over the past two decades [21-23]. In studies in England, the United States and Australia, the incidence of diabetes-related LLA reduced significantly with rates ranging from 5.5 to 36 per 100,000 people in the general population over a decade $[24,25]$. The reduced rate of diabetes-related LLA in industrialised countries compared to those recorded in our study and studies from other LMICs can be attributed to the introduction of multidisciplinary diabetes foot care clinics, streamlined care pathways, and patient education on foot screening [8-13]. Although the study was sited at a tertiary referral hospital where mostly the patients referred, have serious forms of diabetes often with complications,

Table 2 Type of Amputations among study participants

\begin{tabular}{llll}
\hline Type of Amputation & $\begin{array}{l}\text { Total Number } \\
(n=78)\end{array}$ & $\begin{array}{l}\text { Males } \\
(n=62)\end{array}$ & $\begin{array}{l}\text { Females } \\
(n=16)\end{array}$ \\
\hline Major Amputations $(n=53)$ & & & \\
Right Above Knee Amputation & $25(32.0)$ & $20(25.6)$ & $5(6.4)$ \\
Right below Knee Amputation & $13(16.7)$ & $10(12.8)$ & $3(3.8)$ \\
Left Above Knee Amputation & $4(5.1)$ & $3(3.8)$ & $1(1.3)$ \\
Left Below Knee Amputation & $4(5.1)$ & $4(6.5)$ & $0(0)$ \\
Bilateral Above Knee Amputation & $4(5.1)$ & $3(3.8)$ & $1(1.3)$ \\
Bilateral below Knee Amputation & $3(3.8)$ & $3(3.8)$ & $0(0)$ \\
Minor Amputations ( $n=25)$ & & & \\
Right Digital Amputation & $12(15.3)$ & $10(12.8)$ & $2(2.6)$ \\
Left digital amputation & $8(10.3)$ & $5(6.4)$ & $3(3.8)$ \\
Bilateral Digital Amputation & $5(6.4)$ & $4(6.5)$ & $1(1.3)$ \\
\hline
\end{tabular}

the increasing trend of LLA is alarming. However in Ghana, as in most other LMICs where a rising trend of diabetes-related LLA has been observed, measures such as lack of resources, high patient load, absence of suitable facilities and trained personnel have been identified as major contributors [26]. Additionally, in Ghana, the life expectancy of the population including those with diabetes has increased over the years as a result of improvement in the economic conditions of the country with additional implications for medication purchasing abilities as well as improvement in dietary choices [27].

The commonest predictor of diabetes-related LLA in our cohort as revealed by this study was PVD, like findings from other studies in Europe [28, 29]. A general trend has been observed among people with diabetes in LMICs with a shift towards an increase in cardiovascular disease and its risk factors. This was observed in our study, with a high prevalence of uncontrolled vascular risk factors such as hypertension and hyperglycemia. However, only 15.4, 29.5 and $44.9 \%$ of those with diabetes-related LLA were on lipid-lowering, antiplatelet and renin-angiotensin-aldosterone inhibitor therapy at baseline. This therapeutic inertia in the face of overwhelming benefit of these medications collaborates findings that show an association between diabetes-related LLA rates and poor vascular risk factor control among diabetes patients [30]. This situation is compounded by the absence of established vascular imaging services and surgeons in our setting and with other LMICs. Thus any attempt to reduce or treat these vascular complications after they become established is seriously hampered. It is not by coincidence therefore that most studies reporting a decrease in the incidence of diabetes-related LLA in patients with diabetes have been performed by researchers in highly specialised diabetic foot care units as well as those working in centres with well-established vascular services [31].

Our study shows type 2 diabetes patients were at eight times increased risk of diabetes-related LLA. Although 
Table 3 Predictors of Lower extremity amputations

\begin{tabular}{|c|c|c|c|c|}
\hline Predictor & Unadjusted HR (95\% Cl) & $P$-Value & Adjusted HR (95\% Cl) & $P$-Value \\
\hline \multicolumn{5}{|l|}{ Gender } \\
\hline Male & $5.28(3.11-8.96)$ & $<0.001$ & $3.50(2.88-5.23)$ & $<0.001$ \\
\hline Female & 1 & & & \\
\hline \multicolumn{5}{|l|}{ Age at presentation } \\
\hline 10 years' age increase & $1.40(1.19-1.65)$ & $<0.001$ & $1.11(1.06-1.22)$ & $<0.001$ \\
\hline \multicolumn{5}{|l|}{ Duration of diabetes } \\
\hline 5 year increase & $2.40(0.92-3.14)$ & $<0.07$ & - & \\
\hline \multicolumn{5}{|l|}{ Type of DM } \\
\hline Type 1 & 1 & & 1 & \\
\hline Type 2 & $6.20(3.13-9.43)$ & $<0.001$ & $8.21(2.58-10.7)$ & $<0.001$ \\
\hline Specific type & $0.50(0.32-1.21)$ & 0.32 & & \\
\hline \multicolumn{5}{|l|}{ Body mass index } \\
\hline Each $5 \mathrm{~kg} / \mathrm{m}^{2}$ increase & $5.3(3.11-8.96)$ & $<0.001$ & $3.2(2.51-7.25)$ & $<0.001$ \\
\hline \multicolumn{5}{|l|}{ Glycemic control } \\
\hline A percentage increase in $\mathrm{HbA} 1 \mathrm{c}$ & $1.23(1.08-1.42)$ & 0.003 & $1.11(1.05-1.25)$ & 0.03 \\
\hline \multicolumn{5}{|l|}{ Dyslipidaemia } \\
\hline Present & $0.84(0.51-1.36)$ & 0.47 & - & - \\
\hline Absent & 1 & & & \\
\hline \multicolumn{5}{|l|}{ Complications } \\
\hline Hypertension & $1.51(1.02-1.71)$ & $<0.001$ & $1.14(1.12-3.21)$ & $<0.001$ \\
\hline Nephropathy & $1.6(0.8-2.3)$ & 0.07 & - & - \\
\hline \multicolumn{5}{|l|}{ A $10 / \mathrm{mL} / \mathrm{min} / 1.73 \mathrm{~m}^{2}$ drop in eGFR } \\
\hline Peripheral sensory neuropathy & $7.28(6.38-9.21)$ & $<0.001$ & $6.56(6.21-8.52)$ & $<0.001$ \\
\hline Peripheral Vascular Disease & $9.76(5.67-12.21)$ & $<0.001$ & $7.73(4.39-9.53)$ & $<0.001$ \\
\hline
\end{tabular}

type 1 diabetes patients were proportionally lower in numbers compared to type 2 diabetes patients, it is suggested that type 1 diabetes patients are more strictly controlled for glycaemia and other risk factors for diabetic foot disease; in contrast, many patients with type 2 diabetes have less aggressive management of these risk factors as well as an abundance of vascular risk factors usually mediated by insulin resistance [32].

The increasing incidence of diabetes-related LLA brings into sharp focus the care of diabetes patients in Ghana and other LMICs. Since diabetes foot and diabetes-related LLA often serve as an indicator of diabetes management, severity and quality of diabetes care. It may be concluded that diabetes care in the middle belt of Ghana is not optimum. Diabetes care in Ghana as in most LMIC focus attention almost entirely on achieving glycemic targets with a limited effort at improving patient education, self-care practices and control of vascular risk factors such as hypertension and obesity. Patients are therefore left bereft of knowledge, delay in seeking treatment and lack of proper foot care [26].

This study has limitations worth noting. It was conducted in a single centre among a cohort of diabetes patients thus cannot be generalised to the entire Ghanaian diabetes population and indeed LMICs. Additionally, a significant risk of bias is inherent due to the retrospective design and the fact that the study was based on patients from a single centre. This, however, is the first study to the best of our knowledge to provide a detailed assessment of a longitudinal record of LLA among diabetes patients as well as the predictors of LLA in SSA. This study has raised several important questions which are pertinent if we are to reduce the incidence of LLA in resource-limited settings such as ours where health professionals are in short supply, and a severe lack of investigative tools exists. In this environment, effective prevention programs that are feasible, acceptable, timely and sustainable are urgently needed amid a rising epidemic of diabetes and its complications. Thus community-based studies are required to give a clearer picture of the extent of diabetic-related LLA in LMIC and interventions urgently crafted to address them.

\section{Conclusion}

In conclusion, the present study has shown an increased incidence of diabetes-related LLA in a cohort of patients 
with diabetes referred to a tertiary referral centre in Ghana. This increase in the rate of LLA was associated with a high prevalence of vascular risk factors. This call for better management of diabetes and vascular risk factors as well as initiatives to raise awareness and access to services focused on diabetes-related foot health. Also, the availability of advice on other preventive podiatric measures (such as appropriate footwear and strategies to offload pressure points) and regular vascular assessments and other intervention should be increased.

\section{Abbreviations}

BMI: Body Mass Index; HbA1c: Glycated haemoglobin; LLA: Lower Limb Amputations; LMIC: Low middle-income countries; SSA: Sub-Saharan Africa

\section{Acknowledgements}

The authors acknowledge the immense role played by Research assistants at the Diabetes Clinic, KATH.

\section{Funding}

The lead author funded this study

\section{Availability of data and materials}

De-identified data is held securely by the senior author and may be available upon request.

\section{Authors' contributions}

OSK and FSS made substantial contributions to the conception and design data acquisition and analysis of data, and drafted the article. IK made substantial contributions to the analysis of data and drafting of the article. CA and JCM made substantial contributions to the conception and data acquisition and critically revised the article. All authors provided final approval of the version to be published.

\section{Ethics approval and consent to participate}

The study was approved by the Committee on Human Research Publication and Ethics of the School of Medical Sciences, Kwame Nkrumah University of Science and Technology, and the Komfo Anokye Teaching Hospital, Kumasi. We anonymised patient's records/information before analysis.

\section{Consent for publication}

Not applicable on request.

\section{Competing interests}

The authors declare that they have no competing interests.

\section{Publisher's Note}

Springer Nature remains neutral with regard to jurisdictional claims in published maps and institutional affiliations.

\section{Author details \\ ${ }^{1}$ Komfo Anokye Teaching Hospital, Endocrine and Diabetes Unit, P.O Box 1934, Kumasi, Ghana. ${ }^{2}$ Department of Medicine, Komfo Anokye Teaching Hospital/ School of Medical Sciences, Kwame Nkrumah University of Science and Technology, Kumasi, Ghana. ${ }^{3}$ Department of Public Health, Academic Medical Center, University of Amsterdam, Amsterdam, Netherlands. ${ }^{4}$ Faculty of Medicine and Department of Biomedical Sciences, University of Yaoundé 1, Yaoundé, Cameroon.}

Received: 13 January 2018 Accepted: 21 February 2019 Published online: 01 March 2019

\section{References}

1. NCD Risk Factor Collaboration (NCD-RisC). Worldwide trends in diabetes since 1980: a pooled analysis of 751 population-based studies with 4.4 million participants. Lancet. 2016;387:1513-30. https://doi.org/10.1016/ S0140-6736(16)00618-8.
2. Boyle JP, Thompson TJ, Gregg EW, Barker LE, Williamson DF. Projection of the year 2050 burden of diabetes in the US adult population: dynamic modelling of incidence, mortality, and prediabetes prevalence. Popul Health Metrics. 2010;8:29. https://doi.org/10.1186/1478-7954-8-29.

3. Peer N, Kengne A-P, Motala AA, Mbanya JC. Diabetes in the Africa region: an update. Diabetes Res Clin Pract. 2014;103:197-205. https://doi.org/10. 1016/j.diabres.2013.11.006

4. Zhang P, Zhang X, Brown J, Vistisen D, Sicree R, Shaw J, et al. Global healthcare expenditure on diabetes for 2010 and 2030. Diabetes Res Clin Pract. 2010;87: 293-301. https://doi.org/10.1016/j.diabres.2010.01.026.

5. Blay SL, Fillenbaum GG, Marinho V, Andreoli SB, Gastal FL. Increased health burden associated with older Brazilians with diabetes. J Affect Disord. 2011 ; 134:77-84. https://doi.org/10.1016/j.jad.2011.05.012

6. Nemcová J, Hlinková E, Farský I, Žiaková K, Jarošová D, Zeleníková R, et al. Quality of life of patients with diabetic foot ulcer in the Visegrad countries. J Clin Nurs. 2016. https://doi.org/10.1111/jocn.13508.

7. Wraight PR, Lawrence SM, Campbell DA, Colman PG. Retrospective data for diabetic foot complications: only the tip of the iceberg? Intern Med J. 2006; 36:197-9. https://doi.org/10.1111/j.1445-5994.2006.01039.x.

8. Narres M, Kvitkina T, Claessen H, Droste S, Schuster B, Morbach S, et al. Incidence of lower extremity amputations in the diabetic compared with the non-diabetic population: a systematic review. PLoS One. 2017;12(8): e0182081 https://doi.org/10.1371/journal.pone.0182081.

9. Jørgensen ME, Almdal TP, Faerch K. Reduced incidence of lower-extremity amputations in a Danish diabetes population from 2000 to 2011. Diabet Med. 2014;31:443-7. https://doi.org/10.1111/dme.12320.

10. Wilbek TE, Jansen RB, Jørgensen B, Svendsen OL. The diabetic foot in a multidisciplinary team setting. Number of amputations below ankle level and mortality. Exp Clin Endocrinol Diabetes. 2016;124:535-40. https://doi. org/10.1055/s-0042-109260.

11. Chen I-W, Yang H-M, Chiu C-H, Yeh J-T, Huang C-H, Huang Y-Y. Clinical characteristics and risk factor analysis for lower-extremity amputations in diabetic patients with foot ulcer complicated by necrotizing fasciitis. Medicine. 2015;94:e1957. https://doi.org/10.1097/MD.0000000000001957.

12. Krishnan S, Nash F, Baker N, Fowler D, Rayman G. Reduction in diabetic amputations over 11 years in a defined U.K. population: benefits of multidisciplinary teamwork and continuous prospective audit. Diabetes Care. 2008;31:99-101. https://doi.org/10.2337/dc07-1178.

13. Komelyagina EY, Volkovoy AK, Sanbanchieva NI, Zaichikova MF, Maksimov NV, Antsiferov MB. Multidisciplinary team approach for diabetic foot patients in an out-patient clinic. Klin Med (Mosk). 2016;94:127-32.

14. de-Graft Aikins A, Unwin N, Agyemang C, Allotey P, Campbell C, Arhinful D. Tackling Africa's chronic disease burden: from the local to the global. Glob Health. 2010;6:5. https://doi.org/10.1186/1744-8603-6-5.

15. Guell C, Unwin N. Barriers to diabetic foot care in a developing country with a high incidence of diabetes-related amputations: an exploratory qualitative interview study. BMC Health Serv Res. 2015;15:377. https://doi. org/10.1186/s12913-015-1043-5.

16. Ogbera $A O$, Fasanmade $O$, Ohwovoriole $A E$, Adediran $O$. An assessment of the disease burden of foot ulcers in patients with diabetes mellitus attending a teaching hospital in Lagos, Nigeria. Int J Low Extrem Wounds. 2006:5:244-9. https://doi.org/10.1177/1534734606294538.

17. Agu TC, Ojiaku ME. The indications for major limb amputations: 8 years retrospective study in a private orthopaedic and trauma Centre in southEast Nigeria. J Clin Orthop Trauma. 2016;7:242-7. https://doi.org/10.1016/j. jcot.2016.03.006.

18. Baidoo RO. Major extremity amputations: the Koforidua experience. Postgraduate Medical Journal of Ghana. 2016;5(2):68-70

19. Alberti KG, Zimmet PZ. Definition, diagnosis and classification of diabetes mellitus and its complications. Part 1: diagnosis and classification of diabetes mellitus provisional report of a WHO consultation. Diabet Med. 1998:15:539-53.

20. Unwin N. Comparing the incidence of lower extremity amputations across the world. The global lower extremity amputation study. Diabet Med. 1995; $12: 14-8$.

21. Abbott CA, Carrington AL, Ashe H, Bath S, Every LC, Griffiths J, et al. The north-west diabetes foot care study: incidence of, and risk factors for, new diabetic foot ulceration in a community-based patient cohort. Diabet Med. 2002;19:377-84.

22. Wang C, Mai L, Yang C, Liu D, Sun K, Song W, et al. Reducing major lower extremity amputations after the introduction of a multidisciplinary team in 
patient with diabetic foot ulcer. BMC Endocr Disord. 2016;16:38. https://doi. org/10.1186/s12902-016-0111-0.

23. Canavan RJ, Unwin NC, Kelly WF, Connolly VM. Diabetes- and nondiabetesrelated lower extremity amputation incidence before and after the introduction of better-organised diabetes foot care: continuous longitudinal monitoring using a standard method. Diabetes Care. 2008:31:459-63. https:/doi.org/10.2337/dc07-1159.

24. Lazzarini PA, O'Rourke SR, Russell AW, Derhy PH, Kamp MC. Reduced incidence of foot-related hospitalisation and amputation amongst persons with diabetes in Queensland, Australia. PLoS One. 2015;10:e0130609.

25. Robbins JM, Nicklas BJ, Augustine S. Reducing the rate of amputations in acute diabetic foot infections. Cleve Clin J Med. 2006;73:679-83.

26. Dagadu HE, Patterson EJ. Placing a health equity Lens on non-communicable diseases in sub-Saharan Africa. J Health Care Poor Underserved. 2015;26:967-89. https://doi.org/10.1353/hpu.2015.0097.

27. Ofori-Asenso R, Garcia D. Cardiovascular diseases in Ghana within the context of globalisation. Cardiovascular Diagnosis and Therapy. 2016;6(1): 67-77. https://doi.org/10.3978/j.issn.2223-3652.2015.09.02

28. Ran X-W, Zhao J-C. The importance of multidisciplinary foot-care services in the management of diabetic patients with peripheral artery disease and diabetic foot ulcers. Sichuan Da Xue Xue Bao Yi Xue Ban. 2012;43:728-33.

29. Wrobel JS, Robbins J, Armstrong DG. The high-low amputation ratio: a deeper insight into diabetic foot care? J Foot Ankle Surg. 2006;45:375-9. https://doi.org/10.1053/j.jfas.2006.09.015 [44]

30. Lorber D. Importance of cardiovascular disease risk management in patients with type 2 diabetes mellitus. Diabetes Metab Syndr Obes. 2014;7:169-83. https://doi.org/10.2147/DMSO.S61438

31. Mohammed K, Woodward M, Hirakawa Y, Zoungas S, Colagiuri S, Hamet P, et al. Presentations of major peripheral arterial disease and risk of major outcomes in patients with type 2 diabetes: results from the ADVANCE-ON study. Cardiovasc Diabetol. 2016;15:129. https://doi.org/10.1186/s12933-0160446-X.

32. Lai Y-J, Hu H-Y, Lin C-H, Lee S-T, Kuo S-C, Chou P. Incidence and risk factors of lower extremity amputations in people with type 2 diabetes in Taiwan, 2001-2010. J Diabetes. 2015;7:260-7. https://doi.org/10.1111/1753-0407. 12168.

Ready to submit your research? Choose BMC and benefit from:

- fast, convenient online submission

- thorough peer review by experienced researchers in your field

- rapid publication on acceptance

- support for research data, including large and complex data types

- gold Open Access which fosters wider collaboration and increased citations

- maximum visibility for your research: over $100 \mathrm{M}$ website views per year

At $\mathrm{BMC}$, research is always in progress.

Learn more biomedcentral.com/submissions 